\title{
EFFECT OF PULSATILE FLOW ON RENAL FUNCTION IN ELDERLY PATIENTS UNDERGOING CORONARY ARTERY BYPASS SURGERY
}

\section{Amanj Kamal Mohammed}

MB,ChB, FIBMS Cardiovascular Surgery. Cardiac Surgeon, Division of Cardiovascular and thoracic Surgery, Slemani Cardiac Hospital. Department of Surgery, College of Medicine, University of AlSulaymaniyah, IRAQ.

\begin{abstract}
The incidence of acute kidney injury (AKI) after on-pump coronary artery bypass graft (CABG) varies among studies but can be reduced if pulsatile flow is used.

The aim of this study is to evaluate pulsatile flow impact on renal function of elderly patients undergoing $\mathrm{CABG}$.

Over one year (April 2014 to April 2015) 48 patients above the age of 65 underwent on-pump CABG in our institute. Patients were divided into two groups; pulsatile flow (PFG) and nonpulsatile flow (NPFG) groups. Serum creatinine (S.Cr), creatinine clearance (Cr.Cl) and perperfusion urine output (UO) were measured. AKI Network criteria were adopted for diagnosis.

Mean age was 68 in PFG and 69 in NPFG. Males constituted $83.3 \%$ of PFG and $79.2 \%$ of NPFG. Although $37.5 \%$ of PFG and $41.7 \%$ of NPFG were hypertensive, all patients had normal ejection fraction (EF). Both groups had nearly 3 coronary anastomoses, cardiopulmonary bypass (CPB) time of $90 \mathrm{~min}$, cross clamp time of $71 \mathrm{~min}$ and mean perfusion pressure of 70 $\mathrm{mmHg}$. Mean S.Cr was the same $(0.8 \mathrm{mg} / \mathrm{dl})$ in both groups on 1 st postoperative day (POD) but UO was significantly larger (708 $\mathrm{ml}$ in PFG vs. $648 \mathrm{ml}$ in NPFG). On 3rd POD, S. Cr didn't change in PFG but it has significantly increased in NPFG (from 0.76 to $1.0 \mathrm{mg} / \mathrm{dl}$ ). Moreover, $\mathrm{Cr}$.Cl has significantly improved in PFG (81 vs. $72 \mathrm{ml} / \mathrm{min}$ in NPFG). Seven of 48 patients (14.6 $\%$ ) developed AKI (6; 25\% in NPFG).

In conclusion; Pulsatile perfusion technique is a simple and safe measure to minimize AKI in the elderly.

Keywords: Coronary artery bypass graft, elderly, cardiopulmonary bypass, pulsatile flow, non-pulsatile flow, acute kidney injury, serum creatinine, creatinine clearance
\end{abstract}

\section{Introduction}

$A$ lthough coronary artery bypass graft on a beating heart (off-pump), most CABG operations are still performed under cardiopulmonary bypass (CPB). When $\mathrm{CPB}$ is used, it has many unfavorable systemic effects on body organs due to inflammatory reactions ${ }^{1}$ which may lead to organ dysfunction ${ }^{2}$. One of the devastating complications after cardiac surgery is acute kidney injury $(\mathrm{AKI})^{3}$ whose incidence ranges from $0.6 \%-10 \%{ }^{4,5}$. Noteworthy, $20 \%$ of AKI require dialysis and are associated with a high mortality ${ }^{6,7}$. The pathogenesis of AKI after cardiac surgery particularly $\mathrm{CABG}$, is multifactorial. Prolonged aortic cross-clamping time, low perfusion pressure, non-pulsatile flow, hemodilution, embolic phenomenon, oxygen radicals and pro-inflammatory response are few to mention ${ }^{8,9}$.

Regarding the type of $\mathrm{CPB}$; pulsatile flow may provide better microcirculation and tissue perfusion than non-pulsatile flow due to its physiological nature. Peripheral vascular resistance is one of the major determinants that affect tissue perfusion during $\mathrm{CPB}$, and pulsatile flow provides lower peripheral vascular 
resistance and higher blood supply than non-pulsatile flow ${ }^{10,11}$. Advanced age is considered an independent risk factor for renal disease. Previous studies revealed high incidence of acute renal failure in the elderly ${ }^{12}$. However, the exact mechanism of this correlation between renal failure and advanced age is not well-known. The role of comorbidities such as diabetes mellitus, vascular disease, and hypertension is not very clear $^{13}$. The kidney of elderly patient is more vulnerable for injury than that of the young, since it has a decreased vasodilation capacity when stimulated maximally, and it has a great sensitivity to volume depletion ${ }^{14}$.

There are different methods for assessment of renal function, AKI recognition is based on a rise in serum creatinine (S.Cr), blood urea nitrogen (BUN), cystatin $\mathrm{C}$ and creatinine clearance $(\mathrm{Cr} . \mathrm{Cl})$. Serum creatinine and calculated creatinine clearance require a single blood sample testing and, for many decades, have been used for estimation of glomerular filtration rate $(\mathrm{GFR})^{15}$.

This prospective study was carried in order to compare the effects of pulsatile and non-pulsatile $\mathrm{CPB}$ on incidence of AKI in elderly patients undergoing CABG over one year period with review of literature.

\section{Patients and Methods}

This cross-sectional study was conducted in Slemani Cardiac Hospital, AlSulaimaniyah, Kurdistan, Iraq over one year period (April 2014 to April 2015).

Forty eight patients (39 males) were enrolled. Age ranged between 65 and 76 years with a mean of 68.9. All patients underwent $\mathrm{CABG}$ surgery with the use of CPB machine (on-pump). Patients with an ejection fraction (EF) $<50 \%$, history of renal disease, diabetes mellitus and hypertension were excluded. Furthermore, concomitant valve surgery and emergency $\mathrm{CABG}$ were also excluded.
Transthoracic echocardiography (TTE), coronary angiography and renal function tests were performed for all of patients.

All surgeries were performed via median sternotomy incision and CPB was established with ascending aortic cannula and two-stage venous cannula through right atrium. Myocardial protection was achieved via antegrade blood cardioplegia and moderate hypothermia $\left(32^{\circ} \mathrm{C}\right)$. Left internal mammary artery (LIMA) was harvested and anastomosed to the left anterior descending artery (LAD) while great saphenous vein was used a conduit for other coronary arteries. Proximal anastomoses were done with aortic sideclamping.

All patients were monitored intraoperatively by electrocardiography, invasive arterial pressure, central venous catheter, pulse oximeter, and esophageal temperature probe. The standard linear (non-pulsatile) perfusion was used in 24 patients (NPFG) while pulsatile flow was used in the remaining 24 (PFG). In all patients, the mean perfusion pressure was kept within $60-80 \mathrm{mmHg}$.

Renal function was evaluated for all patients by measuring pre-operative serum creatinine, and creatinine clearance using Cockcroft-Gault formula: $\mathrm{Cr} . \mathrm{Cl}$ $($ male $)=([140$-age $] \times$ weight in $\mathrm{kg}) /($ serum creatinine $\times 72)$; (multiplied by 0.85 for

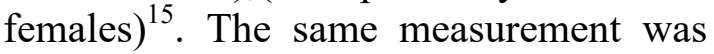
repeated after $\mathrm{CPB}$, and at the third postoperative day. In addition, intra-operative and post-CPB urine output (UO) was measured. In this study, AKI was defined as reduction in urine output (oliguria of $<0.5 \mathrm{ml} / \mathrm{kg}$ per hour for $>6$ hours), $>0.3$ $\mathrm{mg} / \mathrm{dl}$ absolute increase in serum creatinine post-operatively $(50 \%$ rise from the baseline serum creatinine level, a 1.5 fold increase from the baseline) according to AKI Network (AKIN) ${ }^{16}$.

Data were analyzed using IBM SPSS for windows version 25 software and variables of the two groups were compared. P-values $<0.05$ were considered significant. 


\section{Results}

A comparison of preoperatve variables between the two groups is demonstrated in table I.

Table I: Pre-operative Characteristics of Both Groups.

\begin{tabular}{|l|l|l|l|l|l|}
\hline Variable & \multicolumn{2}{l}{$\begin{array}{l}\text { Pulsatile Flow Group } \\
(\mathrm{PFG})(\mathrm{N}=24)\end{array}$} & \multicolumn{2}{l}{$\begin{array}{l}\text { Non-pulsatile Flow Group } \\
(\mathrm{NPFG})(\mathrm{N}=24)\end{array}$} & \multirow{2}{*}{ P value } \\
\cline { 2 - 5 } & $\%$ & Mean \pm SD & $\%$ & Mean \pm SD & \\
\hline Age & --- & $68.79 \pm 3.25$ & --- & $69.13 \pm 3.26$ & 0.725 \\
\hline Male Gender & 83.3 & --- & 79.2 & --- & 0.712 \\
\hline Hypertension & 37.5 & --- & 41.7 & --- & 0.5 \\
\hline EF\% & --- & $56.7 \pm 3.3$ & --- & $57.1 \pm 3.1$ & 0.653 \\
\hline
\end{tabular}

All patients were above the age of 65 (68 years in PFG vs. 69 years in NPFG). Males constituted $>3$ quarters of patients in both groups ( $83.3 \%$ in PFG vs. $79.2 \%$ in NPFG). Hypertension was documented in $37.5 \%$ in PFG vs. $41.7 \%$ in NPFG. All patients had a normal left ventricular EF ( $>55 \%)$. It was almost the same in both groups $(56.7 \%$ in PFG vs. $57.1 \%$ in NPFG). All differences were not statistically significant. The operative variables are shown in Table II.

Table II: Operative Variables.

\begin{tabular}{|l|l|l|l|}
\hline \multirow{2}{*}{ Variable } & PFG $(\mathrm{N}=24)$ & NPFG $(\mathrm{N}=24)$ & \multirow{2}{*}{ P value $(>0.05)$} \\
\cline { 2 - 3 } & Mean $\pm \mathrm{SD}$ & Mean $\pm \mathrm{SD}$ & \\
\hline Mean number of anastomoses & $3.0 \pm 0.5$ & $2.8 \pm 0.45$ & 0.372 \\
\hline CPB time (min.) & $91.7 \pm 5.2$ & $91.0 \pm 5.6$ & 0.692 \\
\hline Cross clamp time (min.) & $70.9 \pm 5.2$ & $70.7 \pm 5.6$ & 0.915 \\
\hline Mean perfusion pressure (mmHg) & $69.2 \pm 6.9$ & $70.9 \pm 6.9$ & 0.405 \\
\hline
\end{tabular}

It is evident that both groups had almost very similar operative variables like mean number of coronary anastomoses $(\simeq 3), \mathrm{CPB}$ time ( $\simeq 90$ minutes), cross clamp time ( $\simeq 71$ minutes) and mean perfusion pressure $(\simeq 70 \mathrm{mmHg})$.

The renal function indicators in the 2 groups of patients are demonstrated in Table III.

Table III: Renal Function Indicators in Both Groups.

\begin{tabular}{|l|l|l|l|}
\hline \multirow{2}{*}{ Indicator } & PFG $(\mathrm{N}=24)$ & NPFG $(\mathrm{N}=24)$ & \multirow{2}{*}{ P value. } \\
\cline { 2 - 3 } & Mean \pm SD & Mean \pm SD & \\
\hline Preoperative S. Cr. $(\mathrm{mg} / \mathrm{dl})$ & $0.76 \pm 0.09$ & $0.76 \pm 0.09$ & $>0.05$ \\
\hline S.Cr after weaning from CPB $(\mathrm{mg} / \mathrm{dl})$ & $0.8 \pm 0.1$ & $0.8 \pm 0.1$ & $>0.05$ \\
\hline 3rd postoperative day S.Cr. $(\mathrm{mg} / \mathrm{dl})$ & $0.9 \pm 0.11$ & $1.0 \pm 0.12$ & 0.002 \\
\hline 3rd postoperative day Cr. Clearance (ml/min) & $81 \pm 7.5$ & $72 \pm 9.5$ & 0.001 \\
\hline Urine output $(\mathrm{ml})$ during CPB & $708 \pm 85.5$ & $648 \pm 59.8$ & 0.007 \\
\hline
\end{tabular}

Early after weaning from CPB, mean serum creatinine was the same $(0.8 \pm 0.1 \mathrm{mg} / \mathrm{dl})$ in both groups. However, on the 3rd postoperative day, serum creatinine and creatinine clearance became significantly different between the 2 groups $(p<0.05)$. In regard to the urine output (just after weaning from CPB), it was significantly better (larger) in the PFG $(708 \pm 85.5 \mathrm{ml}$ vs. $648 \pm 59.8 \mathrm{ml}$ for the NPFG) $(\mathrm{p}<0.05)$.

The distribution of AKI in the 2 study groups is shown in Figure 1. 


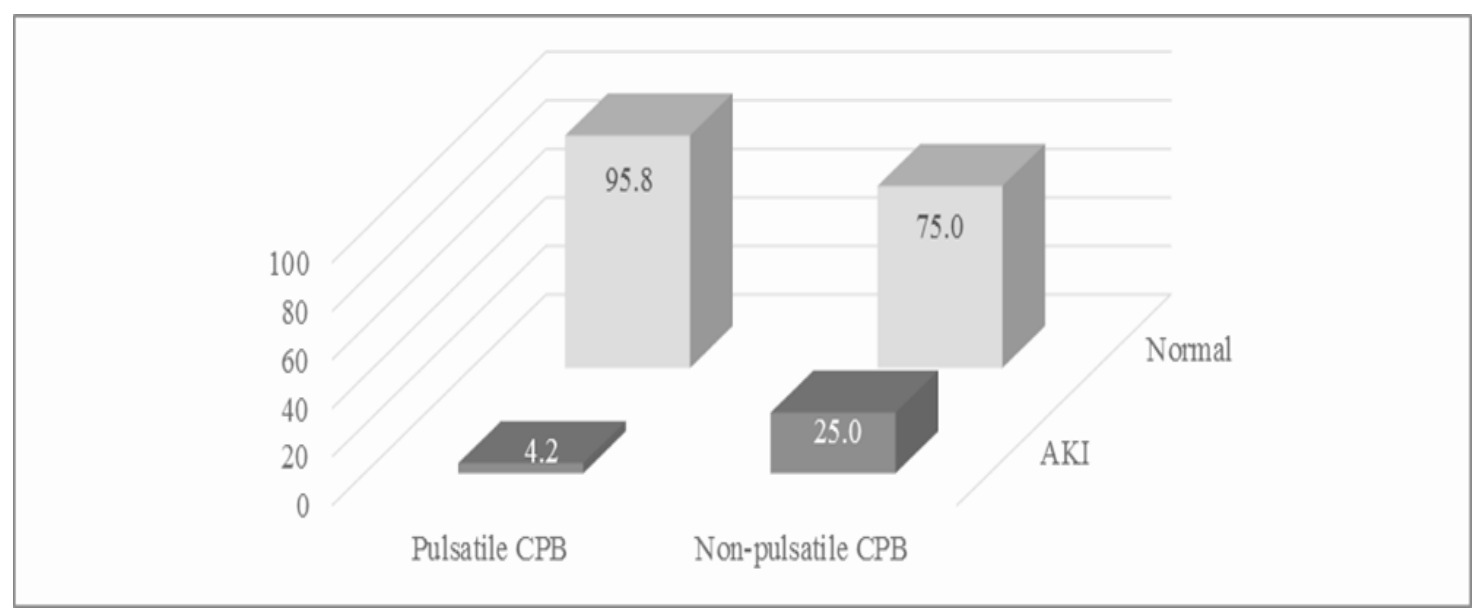

Figure 1: Distribution of AKI in both groups.

Overall 7 of 48 patients (14.6\%) had AKI. All of them were managed conservatively and none required hemodialysis. The incidence of AKI was significantly higher among patients who received non-pulsatile flow $(n=6,25 \%)$, $(P$ value $=0.04)$.

\section{Discussion}

Renal function impairment and AKI after cardiac surgery is multi-factorial. Many studies have demonstrated that AKI is more common in the elderly ${ }^{17-19}$. In addition, the type of CPB flow (pulsatile or non-pulsatile) has also been shown to affect the incidence of AKI after cardiac surgery. As long as the aim of the current study was just to assess the influence of type of perfusion flow, we chose 2 groups of patients almost identical in age (mean age of 69).

Furthermore, diabetic patients were excluded because DM itself is considered an independent risk factor for $\mathrm{AKI}^{20-22}$ and the incidence of AKI is higher in diabetic patients undergoing surgery ${ }^{23,24}$. The 2 groups of patients were not significantly different in the rate of hypertension $(37.5 \%$ vs. $41.7 \%)$ as studies have shown a relationship between AKI and high blood pressure, especially uncontrolled hypertension ${ }^{25}$. Low ejection fraction is associated with reduced renal perfusion. Patients with $\mathrm{EF} \% \leq 45 \%$ had a tenfold increase in the incidence of AKI vs. those with LVEF\% $\geq 45 \%{ }^{26}$. For this reason, patients with low EF were excluded from the study and enrolled those with an EF $>55 \%$. Intraoperative events have a big impact on renal function. CPB time, ACC time, and mean perfusion pressure are strongly associated with the development of AKI post-cardiac surgery, especially after $\mathrm{CABG}^{27-29}$. Fortunately, both groups of patients in this study had almost similar CPB time, ACC time and mean perfusion pressure.

Like other studies ${ }^{15,30}$ serum creatinine, and creatinine clearance were used for evaluation of renal function in this study. Other measures of assessing renal function include estimated glomerular filtration rate ${ }^{30}$ and the calculated creatinine clearance ${ }^{15}$. This study showed a significant correlation between the type of perfusion flow and the postoperative renal function. Pulsatile flow was more protective from the development of postoperative renal impairment and/or AKI. Pulsatile flow preserves renal function better than standard non-pulsatile flow even in patients older than 65 . Hence, pulsatile flow is recommended as the procedure of choice in this subgroup of patients ${ }^{31}$.

In this study, pulsatile flow was associated with a significantly better (larger) intraoperative urine output (708 $\mathrm{ml}$ vs. $648 \mathrm{ml}$ ). Hökenek et $\mathrm{al}^{32}$ reported a similar finding with a total urine output 
of $1025 \mathrm{ml}$ in the pulsatile group vs. 828 $\mathrm{ml}$ in the non-pulsatile group. However, Milano et al. showed no significant difference in the perioperative urine output for either group in aortic valve surgery $(653 \pm 353 \mathrm{ml}$ for pulsatile group vs. $602 \pm 296 \mathrm{ml}$ for non-pulsatile flow group with a $p$ value of 0.60$)^{33}$. Urine output in the aforementioned study was measured during the entire operation and not during $\mathrm{CPB}$ period as we did in our study.

Hökenek et $\mathrm{al}^{32}$ observed that the mean serum creatinine level $(\mathrm{mg} / \mathrm{dl})$ for the pulsatile group $(0.9 \pm 0.2)$ was not significantly different from the nonpulsatile group $(1.0 \pm 0.1)$ on 1 st postoperative day and did not differ significantly from the preoperative level $(0.9 \pm 0.2)$. Likewise, our findings were the same i.e. 1st postoperative day serum creatinine was $0.8 \pm 0.1 \mathrm{mg} / \mathrm{dl}$ for both groups).

However, on the 3rd postoperative day, serum creatinine and creatinine clearance became significantly different between the 2 groups $(p<0.05)$. In the pulsatile group no change in serum creatinine was noticed while in the non-pulsatile group it has significantly increased (from
$0.76 \pm 0.1 \mathrm{mg} / \mathrm{dl}$ preoperatively to $1.0 \pm 0.12 \mathrm{mg} / \mathrm{dl}$ on $3 \mathrm{rd}$ postoperative day). The same was true regarding creatinine clearance i.e. it has significantly decreased in the non-pulsatile group $(72 \pm 9.5)$ compared to the pulsatile group

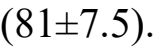

Natarajan et al studied 100 patients divided into 2 groups with similar CPB and ACC times and found that postoperative serum creatinine slightly increased with non-pulsatile perfusion but did not change in pulsatile perfusion ${ }^{34}$. In this study, AKI developed in $25 \%$ of patients who received non-pulsatile perfusion while it occurred in just $2.8 \%$ of patients with pulsatile perfusion $(p<0.05)$. Literature review revealed a great variation in the incidence of AKI after cardiac surgery ${ }^{35,36}$. In this study, 7 of 48 patients (14.6\%) developed AKI while others reported $30 \%{ }^{36}$ and even $43.7 \%{ }^{35}$.

\section{Conclusion}

Pulsatile perfusion technique has a significant effect on the outcome of elderly patients' renal function after cardiac surgery. It is a simple and safe measure for prevention of AKI after coronary surgery in this age group.

\section{References}

1. De Mendonca-Filho HT, Pereira KC, Fontes M, Veira DA, de Mendonca ML, Campos LA, Castro-Faria-Neto HC. Circulating inflammatory mediators and organ dysfunction after cardiovascular surgery with cardiopulmonary bypass: a prospective observational study. Crit Care 2006;10:46.

2. Passaroni A, Silva M, Yoshida W. Cardiopulmonary bypass: development of John Gibbon's heart-lung machine. Rev Bras Cir Cardiovasc. 2015 Mar-Apr;30(2):235-45.

3. Sakai W, Yoshikawa Y, Hirata N, Yamakage M. Effect of remifentanil during cardiopulmonary bypass on incidence of acute kidney injury after cardiac surgery. J Anesth 2017 Dec;31(6):895-902.

4. Nicoara A, Patel UD, Phillips-Bute BG, Shaw AD, Stafford-Smith M, Milano CA, Swaminathan M. Mortality trends associated with acute renal failure requiring dialysis after CABG surgery in the United States. Blood Purif 2009;28:359-63.

5. Ahmadi H, Karimi A, Davoodi S, Movahedi N, Marzban M, Abbasi K et al. Determinant factors of renal failure after coronary artery bypass grafting with on-pump technique. Med Princ Pract 2009;18:300-4.

6. Rodrigues AJ, Evora PR, Bassetto S, Junior LA, Filho AS, Araujo WF et al. Risk factors for acute renal failure after heart surgery. Rev Bras Cir Cardiovasc 2009;24:441-6.

7. Ghani AA, Al Nasar M, Al Shawaf E, Vislocky I. Impact of mild renal impairment on early postoperative mortality after open cardiac surgery. Saudi J Kidney Dis Transpl 2010;21:1081-7.

8. Rosner MH, Okusa MD. Acute kidney injury associated with cardiac surgery. Clin J Am Soc Nephrol 2006;1:1932.

9. Massoudy P, Wagner S, Thielmann M, Herold U, Kottenberg- Assenmacher E, Marggraf G et al. Coronary artery bypass surgery and acute kidney injury--impact of the off-pump technique. Nephrol Dial Transplant 2008;23:285360.

10. Serraino GF, Marsico R, Musolino G, Ventura V, Gulletta E, Santè P et al. Pulsatile cardiopulmonary bypass with intra-aortic balloon pump improves organ function and reduces endothelial activation. Circ J 2012;76:1121-1129 
11. Kim HK, Son HS, Fang YH, Park SY, Hwang CM, Sun K. The effects of pulsatile flow upon renal tissue perfusion during cardiopulmonary bypass: a comparative study of pulsatile and non-pulsatile flow. ASAIO J 2005;51:30-6.

12. Rodger RS. Renal function in the elderly. Br J Urol 1998;82 Suppl 1:65-70.

13. Odden MC, Tager IB, Gansevoort RT, Bakker SJ, Katz R, Fried LF, et al. Age and cystatin C in healthy adults: a collaborative study. Nephrol Dial Transplant 2010;25:463-9.

14. Presta P, Onorati F, Fuiano L, Mastroroberto P, Santarpino G, Tozzo C et al. Can pulsatile cardiopulmonary bypass prevent perioperative renal dysfunction during myocardial revascularization in elderly patients? Nephron Clin Pract 2009;111:229-35.

15. Nankivell BJ. Creatinine clearance and the assessment of renal function. Aust Prescr 2001;24:15-7.

16. Mehta RL, Kellum JA, Shah SV, Molitoris BA, Ronco C, Warnock DG et al. Acute Kidney Injury Network: report of an initiative to improve outcomes in acute kidney injury. Crit Care 2007;11:31.

17. Ali T, Khan I, Simpson W, Prescott G, Townend J, Smith W, Macleod A. Incidence and outcomes in acute kidney injury: a comprehensive population-based study. J Am Soc Nephrol 2007 Apr;18(4):1292-1298.

18. Hsu CY, McCulloch CE, Fan D, Ordonez JD, Chertow GM, Go AS. Community-based incidence of acute renal failure. Kidney Int 2007 Jul; 72(2):208-212.

19. Liangos O, Wald R, O'Bell JW, Price L, Pereira BJ, Jaber BL. Epidemiology and outcomes of acute renal failure in hospitalized patients: a national survey. Clin J Am Soc Nephrol 2006 Jan;1(1):43-51.

20. Saran R, Robinson B, Abbott KC, Agodoa LY, Albertus P, Ayanian J et al. US Renal Data System 2016 Annual Data Report: Epidemiology of Kidney Disease in the United States. Am J Kidney Dis 2017;69(3S1):A7-A8.

21. Gregg EW, Li Y, Wang J, Burrows NR, Ali MK, Rolka D et al. Changes in diabetes-related complications in the United States, 1990-2010. N Engl J Med 2014;370(16):1514-1523.

22. James MT, Grams ME, Woodward M, Elley CR, Green JA, Wheeler DC et al. A Meta-analysis of the Association of Estimated GFR, Albuminuria, Diabetes Mellitus, and Hypertension with Acute Kidney Injury. Am J Kidney Dis 2015;66(4):602-612.

23. Mehta RH, Grab JD, O'Brien SM, Bridges CR, Gammie JS, Haan CK et al. Bedside tool for predicting the risk of postoperative dialysis in patients undergoing cardiac surgery. Circulation 2006;114(21):2208-2216.

24. Parolari A, Pesce LL, Pacini D, Mazzanti V, Salis S, Sciacovelli C et al. Risk factors for perioperative acute kidney injury after adult cardiac surgery: role of perioperative management. Ann Thorac Surg 2012;93(2):584-591. 25. Schold GT. Blood Pressure Control, Acute Kidney Injury and Cardiovascular Events: Separating the Chaff from the Wheat. Am J Nephrol 2019;49:356-358.

26. Vincent JL. Annual Update in Intensive Care and Emergency Medicine 2019. Springer Nature Switzerland AG. 27. Kumar AB, Suneja M, Bayman EO, Weide GD, Tarasi M. Association between Postoperative Acute Kidney Injury and Duration of Cardiopulmonary Bypass: A Meta-Analysis. Journal of Cardiothoracic and Vascular Anesthesia 2012;26(1):64-69.

28. Karim HM, Yunus M, Saikia MK, Kalita JP, Mandal M. Incidence and Progression of Cardiac Surgery-associated Acute Kidney Injury and its Relationship with Bypass and Cross Clamp Time. Ann Card Anaesth 2017 Jan-Mar; 20(1): 22-27.

29. Ostermann M, Hall A, Crichton S. Low mean perfusion pressure is a risk factor for progression of acute kidney injury in critically ill patients - A retrospective analysis. BMC Nephrol 2017;18:151.

30. Jhee JH, Hwang SD, Song JH, Lee SW. Upper Normal Serum Creatinine Concentrations as a Predictor for Chronic Kidney Disease: Analysis of 14 Years' Korean Genome and Epidemiology Study (KoGES). J Clin Med 2018 Nov; 7(11): 463.

31. Presta P, Onorati F, Fuiano L, Mastroroberto P, Santarpino G, Tozzo C, Andreucci M, Renzulli A, Fuiano G. Can pulsatile cardiopulmonary bypass prevent perioperative renal dysfunction during myocardial revascularization in elderly patients? Nephron Clin Pract 2009;111(4):c229-35.

32. Hökenek F, Gürsoy M, Bakuy V, Kavala AA, Demir T, Gülcan F, Kınoğlu B. An evaluation of renal functions in pulsatile and non-pulsatile cardiopulmonary bypass in the elderly. Turkish Journal of Thoracic and Cardiovascular Surgery 2013;21(3):610-615.

33. Milano AD, Dodonov M, Oeveren WV, Onorati F, Gu YJ et al. Pulsatile cardiopulmonary bypass and renal function in elderly patients undergoing aortic valve surgery. European Journal of Cardio-Thoracic Surgery 2015;47(2):291-298.

34. Natarajan K, Jeeva G, Sophia I, Ramachandran V, Vishwanathan B, Ninan B. Is pulsatile perfusion has significant effects on renal function in patients undergoing cardiac surgery? An observational study. Journal of cardiothoracic and vascular anesthesia 2016;30:20-21.

35. Ramos KA, Dias CB. Acute Kidney Injury after Cardiac Surgery in Patients without Chronic Kidney Disease. Braz J Cardiovasc Surg 2018; 33(5): 454-461.

36. O’Neal JB, Shaw AD, Billings FT. Acute kidney injury following cardiac surgery: current understanding and future directions. Crit Care 2016; 20: 187. 